\title{
O Minimalismo e a experiência psicodélica
}

Aline Pires Luz*

RESUMO: Neste artigo estabeleceremos comparações entre a experiência psicodélica e o Minimalismo através do pensamento de Georges Didi-Huberman em seu livro $O$ que vemos, o que nos olha, onde o autor expõe os limites da idealizada tautologia minimalista, pois, como afirma, a ilusão se contenta com pouco e, assim sendo, as aspirações literais do objeto minimalista são frustradas por nossa capacidade associativa e imaginativa, além de tornarem presentes aspectos experienciados através do estado psicodélico.

Palavras-chave: minimalismo, psicodelismo, arte contemporânea

ABSTRACT: In this article we shall seek to establish comparisons between the psychedelic experience and Minimalism through the thought exposed by Didi-Huberman in his book Ce que nous voyons, ce qui nous regarde, where the author tells us about the break of the idealized boundaries of a minimalist tautology because, as he states, little is enough for illusion, and therefore, the minimal aspirations of the literal objects are frustrated by our associative and imaginative ability and beyond that, they present us aspects experienced through the psychedelic state.

Keywords: minimalism, psychedelia, contemporary art

*Aline Pires Luz é bacharel e mestranda em Artes Visuais do Programa de Pós-Graduação em Artes Visuais do Instituto de Artes da UNESP. E-mail: alinepiresluz@gmail.com 
Georges Didi-Huberman, em O que vemos, o que nos olha (2010), apresenta-nos o argumento de que a literalidade do objeto minimalista, o seu desejo de ser visto tal como é, de permanecer em sua materialidade evidente é a expressão da tautologia: uma redundância, uma repetição. O objeto tautológico significa ele mesmo, o óbvio. Segundo o autor, tal desejo de eliminação da composição, da construção de um objeto íntegro que não revele o jogo da relação entre as partes, levaria a uma permanência cínica apenas no que pode ser objetivamente visto. A tautologia recusa qualquer latência que se apresente à visão. Essas latências capazes de surgir em um objeto seria aquilo que nos olha, algo que ali se esconde e que aos poucos ou subitamente vai sendo percebido. No entanto, há ainda outro extremo que espelhará a atitude tautológica: é a atitude da crença. A crença evitará, igualmente, ver as latências de um objeto, porém não as negará, tentará superá-las. A crença é dogmática e alienante.

Didi-Huberman fornece o exemplo de uma latência tumular nos cubos minimalistas. Assemelham-se a túmulos, tumbas. A tautologia negará essa associação dizendo que se trata somente de um cubo. A crença dirá que se trata de simbolismos de morte. Aqui é traçado um paralelo com a religião, que fornece sempre um ideal de vida após a morte, uma transcendência da angústia da tumba, uma tentativa de sublimá-la.

Entre essas duas atitudes, há o que nos olha, a latência, que não é nem tautológica, nem crente. O cubo não é só um cubo, pois sempre associamos uma forma a algo; o cubo possui virtualidades, porém também não se reduz a um simbolismo tumular, não possui esse significado fechado. Os cubos revelam essa possibilidade, mas continuam abertos às latências. Didi-Huberman faz constantemente a defesa da dialética, capaz de revelar, e foge dos sistemas fechados da tautologia e da crença, que alienam.

A tautologia gera o que artistas como Donald Judd e Frank Stella chamam de especificidade do objeto minimalista, um objeto sem ilusão, que apresenta uma configuração total, que não representa nada e sim que se apresenta singularmente como uma entidade.

[...] tratava-se de fornecer algo como uma força à tautologia do what you see is what you see. Tratava-se de dizer que esse what ou esse that do objeto minimalista existe (is) como objeto tão evidentemente, tão abruptamente, tão fortemente e "especificamente" quanto você como sujeito. (DIDI-HUBERMAN, 2010, p. 62) 
A especificidade é então referida como uma força, uma apresentação abrupta, e agressiva, e o fato de ser quase como um sujeito levou à ideia de presença. A especificidade, portanto, não é algo objetivo e sim uma derivação qualitativa, que surge de uma experiência. Enquanto que para Donald Judd, por exemplo, a especificidade do objeto independe do contexto em que ele se insere, para Robert Morris, outro artista minimalista, a especificidade do objeto depende do contexto. O objeto pode ser simples, mas a experiência de perceber sua integridade não é.

Esse apelo à qualidade de ser, à força, à eficácia de um objeto, constitui, no entanto, claramente uma deriva lógica - na realidade, fenomenológica - em relação à reivindicação inicial da especificidade formal. Pois é ao mundo fenomenológico da experiência que a qualidade e a força dos objetos minimalistas serão finalmente referidas. (DIDI-HUBERMAN, 2010, p. 62)

A ideia de experiência permite a ideia de presença do objeto minimalista, ou seja, algo objetivo adquire conotações subjetivas, pois a subjetividade pressupõe um sujeito. Assim, o objeto minimalista revela uma interioridade, uma profundidade, que se contradiz com a idealizada literalidade sem ilusionismos. Essa interioridade são as latências que surgem da experiência face ao objeto. Uma dessas latências é o antropomorfismo, a escala humana implicada em vários objetos, como os de Robert Morris, Tony Smith e as pinturas de Ad Reinhardt. DidiHuberman afirma que esse antropomorfismo é dessemelhante, pois não é uma representação, é uma relação indicial, subliminar, está implicada através da escala.

A mudez do objeto, acrescida de sua especificidade ou presença que the confere a dimensão de sujeito, cria, portanto, uma especificidade silenciosa, inquieta o olhar e provoca latências que suprem esse silêncio, essa ausência. Há constantemente a pulsão de um duplo nas obras minimalistas: próximo/distante, presente/ausente, vivo/morto, pois as formas mínimas, exatas e completas (o cubo) transformam-se em peça de construção, prenhe de virtualidades. A especificidade é algo inanimado que se torna vivo, uma presença, quando algo nela é vislumbrado. Isso é ser específico em sua própria presença. O fato de tal objeto apresentar-se e não representar coloca o sujeito que se encontra face a ele em confronto com sua presença. A aparência objetiva do objeto intensifica essa confrontação já que elimina o aspecto autoral do artista. Acontece aí uma experiência direta e não mediada ou passiva. O artista se coloca como o propositor de experiências. 
É durante, pois, uma experiência, que pode ser a psicodélica, que há a possibilidade de se chegar a essa forte presença do objeto minimal. O estado em que a pessoa é levada durante a experiência psicodélica produz o aumento da qualidade do ver e também favorece as latências da visão e a pareidolia: "todas as formas se baseiam em outras formas". (MASTERS; HOUSTON, 1968, p. 90) A esse respeito, afirmam ainda os autores Robert E. L. Masters e Jean Houston em L'art psychédélique - A arte psicodélica (1968):

Entre os primeiros efeitos, figuram as alterações dramáticas na percepção sensorial - especialmente a visão. De repente, cores e materiais podem parecer dotados de uma beleza e riqueza que nós nunca havíamos visto ainda. Linhas, também, apresentam-se com uma nitidez impressionante, o olhar se fixa em objetos ou detalhes de objetos, e enriquece-os de significados ou Ihes confere uma carga emocional maior.

[...] A visão pode ser distorcida, mas sua acuidade pode muito bem ser intensificada. (MASTERS; HOUSTON, 1968, p.89)'

E ainda:

A noção de espaço é modificada e o tamanho dos objetos pode aumentar ou diminuir, de uma maneira caprichosa como em Alice no País das Maravilhas, ou às vezes de uma maneira marcadamente ligada à reação intelectual ou emocional que cria o objeto. Seres e coisas podem aparecer se uma de suas características latentes tornou-se absolutamente dominante. Se um rosto se parece com um cavalo ou um porco, a pessoa que está tendo as visões pode começar a relacionar essas imagens a caricaturas italianas bem conhecidas do século XVIII. (MASTERS; HOUSTON, 1968, p. 90)²

Se supusermos um objeto minimalista feito em madeira, em que a qualidade do material é deixada em evidência, como em uma obra sem título de 1974, feita por Donald Judd - uma caixa em compensado cujo plano superior é suspenso em alguns centímetros do resto do corpo do objeto e cuja imagem figura no livro de Didi-Huberman (DIDI-HUBERMAN, 2010, p. 51) -, essa superfície de madeira, ou melhor, suas linhas sinuosas características poderiam começar a se mexer na visão de um espectador em estado de experiência psicodélica, estado de manifestação da mente segundo definição dada pelo psiquiatra Humphry Osmond. (MASTERS; HOUSTON, 2000, p. 6) Ao se mexerem, essas linhas poderiam evocar novas formas e ideias antes impensáveis para aquela superfície. 
Os desenhos da madeira podem se tornar chamas dançantes, rios em movimento, camadas de cera que se derretem, etc., transformando a superfície do objeto quase numa tela de projeção, onde o filme projetado são as associações provocadas pelo que há na superfície estimulando as manifestações da mente em estado não ordinário de percepção. Neste sentido, o objeto minimal adquire vida, torna-se verdadeiramente uma presença, durante o estado alucinatório ou de percepções ilusórias a que se é levado. Pode-se dizer que o objeto nos olha por meio de nossas projeções, e que quanto mais a atenção sobre ele se intensifica, mais imerso nele o espectador estará.

As diversas associações produzidas rompem com a tautologia e não se fixam em qualquer ponto, embora tal ocorrência seja possível. Aí então, a experiência psicodélica pode favorecer a atitude de crença, revelando símbolos e os fixando como algo significativo. Outro problema é o da fascinação alienada que tende para a alucinação, criticada por Didi-Huberman, através de uma citação de Walter Benjamim (DIDI-HUBERMAN, 2010, p. 149), conforme veremos mais adiante. A presença do objeto experimentada como um tipo de alucinação deixa obscurecido o fato de que é a evocação de associações da memória com o que se tem no agora o que constrói tal presença. A presença não é uma ilusão ou alucinação; é uma proposição poética aberta.

A fascinação alienada também se manifestaria através do deslumbramento retínico estimulado pelas qualidades materiais das obras minimalistas, tais como espelhos, acrílicos, metais, a pintura industrial uniforme e brilhante de diversas esculturas, a pintura plana do abstracionismo pós-pictórico, a sinuosidade de algumas superfícies tais como os desenhos da madeira, as qualidades foscas de outros materiais. Tudo isso produz um apelo sensorial à faculdade da visão: brilhos e cores saturadas são tanto um efeito advindo da experiência psicodélica e por ela intensificado, quanto uma característica estética em comum com as obras minimalistas.

A fascinação pelas superfícies brilhantes, translúcidas, uniformemente saturadas é descrita por Aldous Huxley em Céu e Inferno como algo arrebatador e provocador do êxtase. "Os metais polidos e as pedras preciosas são tão intrinsecamente arrebatadores que mesmo um vitoriano, até um joalheiro modernista, são artífices do êxtase". (HUXLEY, 1966, p. 70) Ele ainda cita: 
Tudo o que é visto pelos que visitam os antípodas da mente é intensamente iluminado e parece possuir um fulgor que emana de si mesmo. Todas as cores são intensificadas a um grau muito além do encontrado em nosso estado normal, ao mesmo tempo em que se aguça de modo extraordinário a capacidade da mente para identificar ligeiras variações de tonalidades e matiz. (HUXLEY, 1966, p. 59)

Em outro trecho, Huxley destaca o caráter específico do qual emana uma presença que é possível captar nos objetos durante a experiência psicodélica:

A luz e a cor preternaturais são fenômenos comuns a todos os transes visionários. E, de par com elas, surge com igual constância uma sensação de ampliação de valores. Os objetos luminosos que vemos nos antípodas da mente possuem significado, e esse significado é, de certa forma, tão intenso quanto sua cor. Significado, aqui, se identifica com existência, pois nessa região os objetos não existem a não ser para si mesmos. (HUXLEY, 1966, p. 63)

O deslumbre retínico pode ocorrer na obra 37th Piece of Work (1970) de Carl Andre, uma obra que utiliza seis tipos diferentes de metais ( $\mathrm{Al}, \mathrm{Cu}, \mathrm{Fe}, \mathrm{Mg}, \mathrm{Pb}, \mathrm{Zn}$ ), ou seja: alumínio, cobre, ferro, magnésio, chumbo e zinco, agrupados por ordem alfabética, conforme a sigla da tabela periódica. A obra evoca brilhos, cores e mesmo texturas diferentes, entremeadas numa malha modular.

A capacidade de expansão ad infinitum, outra característica da obra modular de Carl Andre, nos leva à ideia de imersão, de envolver o espectador em um campo total. A fusão da obra com o ambiente passa do campo da especificidade do espaço literal para o campo da presença, criando um tipo de experiência sutil e monástica. Conforme David Batchelor em Minimalismo:

Não passando muitas vezes de $0,5 \mathrm{~cm}$ de altura, esses trabalhos quadrados, retangulares ou lineares dificilmente podem ser visíveis se a cor do metal for similar à do piso da galeria. No entanto, não são frágeis nem efêmeros. Não se impõem ao espectador, mas ao mesmo tempo são indiscutivelmente presentes. Mais do que qualquer trabalho dos outros artistas, sua presença é quieta, estática e quase monástica em sua simplicidade desornada. (BATCHELOR, 2001, p. 62)

Voltando à questão do deslumbre retínico com relação às superfícies, constatamos que isso pode levar a uma atitude de crença, a uma atitude de fascinação alienada que impediria de ver o entremeio, que impediria de estabelecer uma relação dialética. O deslumbre leva à emoção, ao êxtase e pode revelar um caráter religioso ao romper com a superfície tautológica. Essa 
atitude de fascinação nos leva também a revisitar o conceito de aura, o que é feito por DidiHuberman, quando destaca que uma das características desse olhar que nos lança o objeto é justamente a aura. A presença, a latência, as significações se devem à aura do objeto. No entanto, a aura é revisitada do ponto de vista dialético, não crente. Ela se torna secularizada nos objetos minimalistas, onde não há referências iconográficas religiosas e muito menos o aspecto de produção artesanal, o que retira a obra de um valor de culto religioso, pois ela pode ser facilmente reproduzida. No entanto, a fenomenologia da aura permanece e é explicitada.

Segundo Didi-Huberman, a aura se estabelece como o jogo entre o próximo e o distante, uma aparição que vem de longe. Seria a evocação de imagens da memória involuntária despertadas pelo objeto. A fenomenologia da aura tem muito a ver com a imagem dialética, principalmente no que tange ao seu aspecto anacrônico: o passado (memória) vive no encontro com o tempo presente. Porém não se trata de uma rememoração arcaica e sim da contribuição da memória na crítica da imagem presente, formulando continuamente novas imagens num fluxo fragmentado, não linear.

Assim sendo, uma série de latências podem ser sobrepostas constantemente atualizando o objeto, trazendo-lhe dimensões passadas, ausentes, porém em contínuo presente em transformação. A imagem dialética joga constantemente com o paradoxo, com a dupla distância: aparições que até então estavam ausentes, distantes, que atacam a visibilidade presente, colocando-a em metarmorfose. São como flashes, vislumbres que, ao aparecerem, se tornam próximos, porém nunca deixam de estar distantes, pois são um momento único, estranho, misterioso e intangível. Assim se dá a aura e tem-se aí a sua aproximação da esfera religiosa, onde ela é concebida como uma aparição do além, um poder realmente investido no objeto de nos olhar, a fascinação alienada que tende para a alucinação e que cristaliza o vislumbre na crença.

Compreender-se-á aos poucos que, para Benjamim, a aura não poderia se reduzir a uma pura e simples fenomenologia da fascinação alienada que tende para a alucinação. É antes de um olhar trabalhado pelo tempo que se trataria aqui, um olhar que deixaria à aparição o tempo de se desdobrar como pensamento, ou seja, que deixaria ao espaço o tempo de se retramar de outro modo, de se reconverter em tempo. (DIDI-HUBERMAN, 2010, p. 149) 
A secularização busca revelar sua fenomenologia e mostrar que não há ilusionismo e nem alucinação, mas sim um constante fluxo associativo que provém da memória involuntária e do inconsciente e que constrói a poética da obra. A aura participa assim do paradigma do sonho: "[...] todos os tempos nela serão trançados, feitos e desfeitos, contraditos e superdimensionados. Como surpreender-se que apareça aqui o paradigma do sonho [...]". (DIDI-HUBERMAM, 2010, p. 149) E ainda: "É preciso secularizar a aura, é preciso assim refutar a anexação abusiva da aparição ao mundo religioso da epifania". (DIDI-HUBERMAN, 2010, p. 157)

Assim, a fascinação e o deslumbre retínico da experiência psicodélica fazem-se presentes no mundo na crença através da cristalização do ver, uma espécie de cegueira geradora de um estado de transe, ou através da evocação de um estado místico de revelação única, que ocorre nos níveis mais profundos da experiência. A epifania da verdade alcançada.

Os níveis mais profundos da experiência psicodélica são designados por Robert E. L. Masters e Jean Houston (2000, p. 142-313) como sendo os níveis simbólico e integral. Os autores dividiram a experiência em quatro níveis: estético, analítico, simbólico e integral. O nível estético, mais superficial, é onde as alterações visuais, sonoras, auditivas, gustativas, olfativas e táteis ocorrem. É o nível sensorial e também o mais comum. O nível analítico é onde ocorrem divagações sobre conteúdos da memória e também sobre os atuais conteúdos da experiência. O nível analítico produz maior percepção interior, entra-se em um processo similar a uma autoanálise. O nível simbólico é um aprofundamento do nível analítico, onde o sujeito é capaz de encontrar explicações universais para suas indagações, onde pode ocorrer o surgimento de arquétipos, símbolos ou mitos que lhe forneçam aclaramento. Distancia-se do particular e aproxima-se do universal. A experiência religiosa pode ocorrer aqui. A dimensão ritual pode ser proposta quando a experiência é coletiva ou possui um guia. O nível integral é descrito como um estado de iluminação: o sujeito acha-se numa integração total de sua personalidade, conceitualmente descrita como iluminação. Relatos de experiências místicas costumam ocorrer nesse nível, também descrita como uma experiência única, incomunicável por natureza. O interessante é notar certa semelhança com o primeiro nível: algo além da linguagem, uma sensação pura.

A atitude de crença, portanto, pode ocorrer nos níveis simbólico e integral, onde uma explicação é alcançada, uma explicação de caráter universal. Uma ideia de essência imutável, como 
no caso dos arquétipos. Porém, os níveis simbólico e integral levam à transformação pessoal, o que se opõe à alienação. (MASTERS; HOUSTON, 2000, p. 147-150) Outro ponto que pode distanciar as ocorrências desses níveis da atitude de crença é o surgimento do simbolismo, o que é uma ocorrência em comum com o paradigma do sonho, pois o mesmo se dá em linguagem simbólica e participa da fenomenologia da aura.

Quando há a ocorrência da aparição da aura, há uma quebra da estabilidade da superfície ocasionando seu aprofundamento. A qualidade aumentada do ver da experiência psicodélica produz igualmente esse rompimento da superfície, revelando nuances. Outra colocação que a afastaria da crença é que a fascinação retínica acontece no nível sensório e primário da experiência, em seu nível estético. Didi-Huberman, por meio de conceitos advindos de MerleauPonty, afirma que:

[...] o mundo estético - no sentido da aisthésis, isto é, da sensorialidade em geral - nada tem de estável para o fenomenólogo; a fortiori o da estética - no sentido do mundo trabalhado das artes visuais-, que não faz senão modificar as relações e deformar os objetos, os aspectos". (DIDI-HUBERMAN, 2010, p. 163)

Portanto, o mundo da estética não é estável, assim como também não é o nível estético da experiência psicodélica. A instabilidade de tal mundo, que gera distorções e latências sempre possíveis, alinha-se com o paradigma do sonho que revela significados inconscientes ou recalcados e que geram símbolos que estão sempre em processo de transformação.

É assim que se entrelaçam, na aura, a onipotência do olhar e a de uma memória que se percorre como quem se perde numa "floresta de símbolos". Como negar, com efeito, que é todo o tesouro do simbólico - sua arborescência estrutural, sua historicidade complexa sempre relembrada, sempre transformada - que nos olha em cada forma visível investida desse poder de "levantar os olhos"? Quando o trabalho do simbólico consegue tecer essa trama de repente "singular" a partir de um objeto visível, por um lado ele o faz literalmente "aparecer" como um acontecimento visual único, por outro o transforma literalmente: pois ele inquieta a estabilidade mesma de seu aspecto, na medida em que se torna capaz de chamar uma lonjura na forma próxima ou supostamente passível de posse. (DIDI-HUBERMAN, 2010, p. 150)

Encontramos em Ken Johnson, autor do livro Are You Experienced? How Psychedelic Consciousness Transformed Modern Art (2011), ainda mais evidências que podem ligar o Psicodelismo ao Minimalismo com relação ao fenômeno da cor saturada: 
[...] os artistas californianos que trabalhavam a Luz e o Espaço e faziam parte do movimento Finish Fetish tentaram transmitir ou simular tal fenômeno limítrofe-sobrenatural nos anos $60 \mathrm{e}$ 70, frequentemente através do uso de novas tecnologias e materiais sintéticos.

As formas plásticas coloridas de Craig Kauffman e as placas e colunas brilhantes e minimalistas de John McCracken podem dar a impressão da cor como substância maleável. James Turrell tem criado obras de cores aparentemente libertas no espaço através do posicionamento de luzes coloridas atrás de extremidades, fora do campo de visão, através de aberturas dentro das paredes de galerias escurecidas. (JOHNSON, 2011, p. 56-57)

James Turrell tem sua obra centrada em efeitos psicológicos, perceptivos e retínicos. Turrell contrapõe à característica da luz visivelmente provinda de um objeto, como vemos em Dan Flavin por exemplo, a cor imaterial sem ligação visível direta com qualquer fonte de emanação, o que criaria um campo total (ganzfeld), uma espécie de fog onde não há informação espacial ou temporal, onde as fronteiras do espaço estão borradas, indefinidas. (DALY, 1984, p. 172)

Os ganzfelds de James Turrell provocam, portanto, a experiência de imersão na cor saturada e materializam tridimensionalmente a idealizada uniformidade íntegra e literal da superfície minimal tal como foi expressa nas pinturas da abstração pós-pictórica de Frank Stella, Ellsworth Kelly, Ad Reinhardt, entre outros. A cor de fato está desencarnada, possui espacialidade e é uniforme. No entanto, conforme o estímulo visual se intensifica por meio da saturação, a disrupção da superfície ocorre. Cria-se então o jogo do próximo e do distante, nuances são percebidas. Tal como a pintura de Ad Reinhardt, a superfície negra revela gradações ao olho atento. Ocorre aí a fenomenologia da aura.

Em Robert Morris, temos o mesmo princípio. Sua obra sem título, apresentada entre 1968 e 1969, que se constituía tão somente da exalação de um vapor é descrita por Didi-Huberman como a materialização da aura, pois o vapor é algo inefável que ora está, ora não está. (DIDIHUBERMAN, 2010, p. 166)

Em Tony Smith, o negrume volumoso de suas esculturas revela semelhança com os fogs de James Turrel. No entanto, tal negrume se relaciona mais com a privação sensorial, com a sensação de ausência onde não há a produção de estímulo, do que com o estímulo homogêneo constante do ganzfeld. O que em Tony Smith é uma ausência, em James Turrell é uma presença. O cubo negro remete ao vazio, à escuridão, à privação sensorial. Tal privação é ausência 
que inquieta e produz uma latência. O ganzfeld é a saturação sensorial que cria uma ausência, uma cegueira temporária que logo se preencherá com as latências reveladas pela disrupção da uniformidade.

Seguindo nesse jogo do próximo e do distante, da ausência e da presença, temos, em caráter de resumo e conclusão, que as obras minimalistas presentificam experiências estéticas e, portanto, sensoriais. Tornam presente algo daquilo que é temporal. Conforme vimos, o mundo estético não é estável, pois os sentidos estão sempre captando estímulos, criando assim o espaço para as latências, deformações e novas formações. Tais experiências presentificadas pelo Minimalismo são passíveis de ocorrer durante a experiência psicodélica em seus quatro níveis, produzindo tanto as constantes mutações da imagem dialética quanto experiências que levam ao mundo da crença.

Artigo recebido em outubro de 2013, aprovado em novembro de 2013 e publicado em dezembro de 2013.

\section{Notas}

1. Reproduzo aqui o texto original de Masters e Houston por mim traduzido: "Parmi les premiers effets, figurent des changements radicaux de la perception sensorielle - notamment de la vue. Tout à coup, couleurs et matières peuvent sembler dotées d'une beauté et d'une richesse dont on ne s'était encore jamais aperçu. Les lignes, elles aussi, se présentent avec une étonnante netteté; l'attention se fixe sur des objets ou des détails d'objets, et les enrichit d'une signification ou d'une charge émotionnelle plus forte. “[...] La vision peut être faussée mais son acuité peut tout aussi bien être itensifiée. Bien souvent, le monde se revêt de caractères magiques et beaux."

2. É este o texto original de Masters e Houston traduzido por mim no corpo do artigo: "La notion d'espace est faussée et la taille des objets peut croître ou décroître, aussi capricieusement que dans Alice au Pays des Merveilles, ou parfois d'une façon nettement rattachée à lá réaction intellectuelle ou émotionnelle que suscite l'objet. Êtres et choses peuvent apparaître comme si un de leurs caractères latents était devenu absolument dominant. Si un visage est légèrement chevalin ou porcin, son possesseur se met à ressembler à ces caricatures italiennes bien connues du XVIII siècle."

3. O texto de Ken Johnson aparece no artigo traduzido por mim. Em sua versão original, assim se configura: "[...] California artists of the Light and Space and Finish Fetish movements tried to convey or simulate such borderline-supernatural phenomena in the '60s and '70s, often through the use of new technologies and synthetic materials. Craig Kauffman's colored plastic forms and John McCraken's shiny, minimalist slabs and columns can give the impression of color as malleable substance. James Turrell has created 
works of apparently free-floating color by placing colored lights behind the edges, out of sight, of opening cuts into the walls of darkened galleries."

\section{Referências}

BATCHELOR, David. Minimalismo. Coleção Movimentos da Arte Moderna. $2^{\text {a }}$ ed. São Paulo: Cosac \& Naify, 2001.

DIDI-HUBERMAN, Georges. O que vemos, o que nos olha. Trad. de Paulo Neves. $2^{\text {a }}$ ed. São Paulo: Editora 34, 2010.

HUXLEY. Aldous. As portas da percepção: Céu e inferno. São Paulo: Globo, 2002.

JOHNSON. Ken. Are You Experienced? How Psychedelic Consciousness Transformed Modern Art. Munique, Londres, Nova York: Prestel, 2011

MASTERS, Robert E.L.; HOUSTON, Jean. L'art Psychédélique. Paris: Pont Royal / Del Duca / Laffont, 1968.

MASTERS, Robert E.L.; HOUSTON, Jean. The Varieties of Psychedelic Experience: the Classic Guide to the Effects of LSD on the Human Psyche. Rochester: Park Street Press, 2000

\section{Artigos}

BEVERIDGE, Patrick. Color Perception and the Art of James Turrell. Leonardo, v. 33, n. 4, p. 305-313, 2000. Disponível em: <http:// www.jstor.org/stable/1576905>. Acesso em: 01/12/2012.

DALY, Scott. The Ganzfeld as a Canvas for Neurophysiologically Based Artworks. Leonardo, v. 17, n. 3, p. 172-175, 1984. Disponível em: <http://www.jstor.org/stable/1575185>. Acesso em: 19/05/2013. 